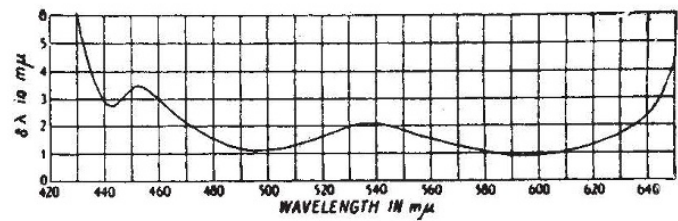

Fig. 5. Human colotr discrimination according to Wright AND PITT ${ }^{8}$.

There are also minor differences in the location of the photopic luminosity curves between protanopic and deuteranopic colour blindness. These are best explained as differences in the proportions of the modulators making up their aggregate dominators.

Since the modulators, which are the physiological units of colour reception, represent a finer mechanism of colour reception than the one envisaged by the trichromatic theory, it is perhaps for this reason that colour matches with three primaries never are perfect in saturation. Nature uses a greater number of primaries, at least six or seven modulators, and, possibly, a still greater number of narrow sensitivity bands within the three preferential regions of the spectrum.

A full account of this work will be published in J. Neurophysiol., vol. 8, 1945.

${ }^{1}$ Granit, Nature, 151, 11 (1943).

2 Wright, Proc. Roy. Soc., B, 115, 49 (1934).

sythgoe, J. Physiol., 89, 331 (1937).

- Schneider, Goodeve and Lythgoe, Proc. Roy. Soc., A, 170, 102 (1939).

${ }^{3}$ Granit, Acta physiol. Scand. 5, 219 (1943).

${ }^{6}$ Wright, Nature, 151, 720 (1943).

? Walters, Proc. Roy. Soc., B, 131, 27 (1942).

${ }^{8}$ Wright and Pitt, Proc. Phs s. Soc., 46, 459 (1934).

${ }^{3}$ Coblentz and Emerson, Bull. U.S. Bureau Stand., No. 303 (1917).

\section{THE FUTURE OF X-RAY ANALYSIS*}

\section{By PROF. J. D. BERNAL, F.R.S. Birkbeck College, London}

I HAVE been out of contact with X-ray analysis for the last six years; this is both an advantage and a disadvantage. Because I know little of its present state, I shall not fail to see the wood for the trees; I can follow the trends, but I am certain to be wrong in detail.

The predictable future is the rational projection of the past and the present, so I shall begin by tracing the major stages of $\mathrm{X}$-ray analysis in the last thirtythree years. The first stage, the Bragg period, as it may well be called, was that in which all the basic structures were worked out. The first edition of "X-Rays and Crystal Structure" contained a specimen of every basic type. It could not have been realized at the time, but every structure since has been an slaboration of one or other of these types. The same is true of methods; all were then known in embryo. The next period was one of rapid development; the silicates were elucidated, then the alloy structures, and a beginning was made in organic compounds with long-chain compounds, aromatics and fibre structures. The number of papers on crystal structure rose rapidly until 1933 , then fluctuated about a mean. This date may be taken as the end of the heroic age

* Substance of an evening lecture to the 1945 Conference of the X-Ray Analysis Group of the Institute of Physics, delivered at the Royal Institution on April 12. of X-ray analysis. It was then realized that the new structures would be essentially like the old ones, and interest was directed towards new and more complex phenomena. From then until the outbreak of war, activity centred round such matters as order-disorder transformations, isomorphous replacement, equilibrium diagrams and biological molecules. During the War there has been an almost complete cessation of academic crystallography; but X-ray analysis has given valuable assistance to other branches of science and industry.

What will happen when it is possible to resume a rational programme of research after the War? The only guarantee of the progress of applied science lies in keeping a proper balance between it and pure science. I believe that 'pure' $\mathrm{X}$-ray analysis will find new fields, more and more complex structures, and show a great development of analytic methods, while 'applied' X-ray analysis 'will become as essential a tool for other fields of research as the microscope and the spectroscope have been in the past.

\section{Substances to be Investigated}

In inorganic chemistry not even the simpler fields have been completely covered, but enough has been done to consider the rest as 'mopping-up' operations. There are still, however, a few groups of compounds not well understood. The first is that of the compounds of boron and carbon with other light elements. These have homopolar bonding, are very hard, and have high melting points. They may contain interstitial metal atoms, and their electrical properties are interesting. Diamond is the only one that has been worked out properly. Another group that will claim attention is the sulphides and the sulpho-salts - compounds of sulphur, arsenic and antimony with metals. They are of major interest to the geochemist, and may throw light on the genesis of metallic ores. There is also work to be done on the oxy-acids, and on the types of Wernerian complexes, the variety of which verges on the organic.

In the field of organic chemistry, there is no future in attempting to find the structures of all erystalline compounds. The basic elucidations of some typesaromatics and sterols-have given keys to organic structure determination, and interest will centre on the nature of the bonds between atoms in the molecules and those between neighbouring molecules. Chemists outnumber erystallographers by about fifty to one, so that crystallographers must make the best use of their time; they must tackle things with soluble structures, but things the chemical nature of which is unknown. One of the triumphs of crystallography during this War has been the complete determination of the structure of one extremely important compound before the chemists had unravelled its structural formula. Many substances of great chemical difficulty will be tackled in the same way.

Beyond the ordinary compounds of organic chemistry there lies the wide range of complicated biological molecules of which the proteins are the best known but by no means the only type. Intense work will undoubtedly continue both on the crystalline and fibrous states of these compounds. The structure of the proteins, fundamental to the understanding of living processes, will not yield to X-ray analysis alone; the attack must be combined with biochemical, centrifical, electrophoretic, electron microscope and other methods, but there is no doubt that X-rays will play a crucial part in verifying all 
hypothetical structures put forward on any other basis.

\section{Physics}

In the field of X-ray physies, interest will be concentrated on the secondary phenomena of diffraction : thermal spots, side-bands, Preston streaks, the effect of temperature on the 'micellar' structure of real crystals. There will be the development of such things as Guinier's central-spot methods, photography at high and low temperatures, high-intensity sources. $\mathrm{X}$-ray tubes in current use are still at the Röntgen level, and a revolution in camera- and tube-design may be expected very soon. Goldstaub and Guinier have already shown how the electron beam can be controlled as in an electron microscope and focused to a tiny spot, so that a current of $0.1 \mathrm{~mA}$. will do as much as $50 \mathrm{~mA}$. now. There is a trend toward the use of smaller cameras; and with better tubes timeexposures will become snapshots. Filters are anachronisms, and crystal-reflected, monochromatized radiation will be the rule.

There must be great development of analytic methods and means of calculation. We are only at the beginning of the development of mechanical and optical methods, and their improvement is very necessary as calculations are becoming a bottle-neck. There is no use in being able to take photographs in a fow seconds if the calculations take months.

\section{Applications}

So far, I have spoken only of straight structural analysis. There is another side to the story: the applications of X-ray analysis to other problems. This will form a larger and larger part of X-ray work. The difficulty has been that the X-ray tube and camera were considered a mysterious and dangerous instrument. People have had three hundred years to get used to the optical microscope, but only thirty to get used to X-rays. The result is that $\mathrm{X}$-rays are not utilized to anything like the extent that they should be. Only the crust has been broken in their industrial application.

I see two fields of organized effort. First there will be highly concentrated specialist $\mathrm{X}$-ray laboratories in universities and big firms. There will be comparatively few of these, not more than one per university or institute. Secondly, there will be standardized equipment available in every laboratory that can usefully employ it. X-ray tubes will be as universal as spectroscopes, and powder cameras as microscopes. The field of $\mathrm{X}$-ray analysis ranges from well-established techniques, as in the metal industry, to the almost unexplored problem of humus formation.

In the metal industry many standard techniques are in use, such as those for the identification of materials, measurement of strain, measurement of grain size. There is considerable use of $\mathrm{X}$-rays in the refractory, ceramic and glass industries-as a rough generalization one might say that the closer an industry is to metallurgy, the more satisfactory is the situation. In cement manufacture, $\mathrm{X}$-rays are used chiefly for quality control, and the industry would benefit greatly from an extension of their use to the examination of raw materials and of the setting process of cement. In the chemical industry a start has been made, but it is only a start, even in the heavy chemical field. Light chemicals have scarcely been touched, and the food industry offers a great opportunity. It is true that the substances to be investigated are 'messy', and do not give good photographs, but there is no reason to suppose that the mathematics of their interpretation cannot be worked out.

In agriculture a small beginning has been made in the identification of soil minerals, but the whole question of soil profiles and the formation of humus remains to be examined. Nagelschmidt's and Mathieu's work in this field marks the beginning of the physical understanding of soils, and its development will lead to the replacement of the present 'mysticism' by knowledge. In geology, geophysics and geochemistry $\mathrm{X}$-ray analysis will have a great part to play. Goldschmidt's study of minerals has led to modern geochemistry. Study of stresses in strata and similar problems will lead to a rational development of geophysics. Though it sounds a contradiction in terms, what is needed is an Institute of Experimental Geology, where geological processes can be reproduced and studied in detail.

\section{The Task of Crystallographers}

It would be futile to consider these prospects without discussing the means for their realization. We have a great task before us if our opportunities are not to be missed. First, we must ensure that there are enough trained people. I hope that, after the War, X-ray analysis will have a larger part in university curricula. A little of it is taught somewhere, usually in chemical or geological departments in most universities, but the only full-scale course is at Cambridge. It is up to the universities to provide greater facilities for both graduate and undergraduate instruction. The Cambridge summer schools in industrial crystallography have made a good start and should be a regular, but probably not a permanent, feature. When crystallography has found its proper place in the normal curriculum, such schools will be needed for whatever is the now subject at that time.

Secondly, there is need for improvement and standardization of apparatus. We know how difficult it is to get apparatus made to our own specifications, since the numbers required are not large enough to make commercial production profitable. We may hope that standardization will remedy this, and that it will no longer be necessary to put up with homemade apparatus. We must first, however, develop reasonable and practicable designs for all necessary apparatus. Our laboratory workshops will still be necessary, but they will be free to work on new equipment instead of spending most of their time making copies of old apparatus. An interesting thing I have noticed is the slowness of the diffusion of material techniques from one laboratory to another, even in the same country. When refitting after the War, we must make the best use of ideas that have been developed in countries other than our own. It is interesting to find that the X-Ray Analysis Group of the Institute of Physics is working on a new method of agreed specifications.

Thirdly, there is the question of publications. Before the War, crystallographic papers appeared in fifty-seven different journals, and of these only the Zeitschrift für Krystallographie was devoted wholly to crystallographic work. We must work for some sort of centralization. One big task is the tidying up of existing knowledge. No one has time to read everything published. A good deal of early work may be wrong, and in any event the detailed measurements 
are inexact. We need some sort of a permanent up-todate loose-leaf 'Strukturbericht'-an X-ray analogue of Groth's "Chemische Krystallographie". In pre-war days Germany was the major stronghold of such systematizing activity; but it is unlikely to be so again, at any rate for some time after this War, so we must share it out. The "X-Ray Index" is a small beginning. Crystallographers in the past have been good at co-operative international activity; the "International Tables" are one outstanding example. We may confidently expect similar success in the future.

\section{International Aspects}

Soon it will be possible to resume international contacts. In Great Britain we do not realize how much X-ray analysis has been a British subject. It has struck no deep roots in other countries, but we shall all be the gainers if others work as intensely as we. I look forward to a spread of crystallographic activity all over the world, with increasing benefits to mankind.

\section{ANOMALOUS INACTIVATION OF HEAVY METAL ANTIFOULING PAINTS*}

\section{By Dr. G. H. YOUNG and G. W. SEAGREN Mellon Institute. Pittsburgh, $\mathrm{Pa}$.}

$\mathrm{T}$ HAT ordinarily effective antifouling paints occasionally show very poor performance, or suddenly begin to foul severely after a period of satisfactory functioning, is an observation familiar to every user of marine paints. In the case of compositions carrying metallic copper, such failures have been almost universally attributed to 'galvanic coupling' with the steel hull-the implication being strong that such paints can and do act in a manner entirely analogous to a gross sheet of copper. In an effort, therefore, to establish the real truth of this matter, the phenomenon of inactivation with both metallic copper and cuprous oxide paints has been under study by us for some time. We have already shown that accidental or deliberate contact of the steel hull with either type of copper-bearing paint can lead to serious pitting at the contact point and to accelerated corrosion attack at adjacent bare areas or 'holidays'1,2. An equally if not more serious result of failure to separate properly the antifouling paint from the steel hull by adequate barrier coats is a decreased effectiveness or even complete inactivation of the antifouling coat ${ }^{1}$.

While certain of our experiments are still uncompleted, we have already established that contactinactivation can happen with cuprous oxide paints as readily as with metallic copper paints ${ }^{1}$. The antifouling efficiency of both types is rapidly lost if they are applied over bare steel ; within three months of immersion they are as badly fouled as are control panels carrying no antifouling paint. As many of these formulations have demonstrated satisfactory antifouling action if applied in the conventional manner over the ustial primer and anticorrosive coats, or if applied to wood, it seems established that their immediate proximity to corroding steel is

- Contribution from the Stoner-Mudge, Inc., Multiple Industrial Fellowship on Protective Coatings at Mellon Institute.

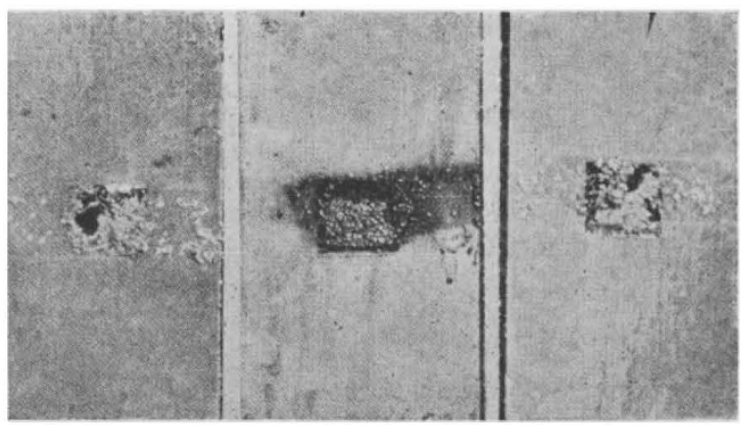

Fig. 1. CharaOteristio BaNDED fouling adjaChNT to BREAK IN PAINT FIJJM.

responsible for the inactivation. It is important to note that this inactivation seldom manifests itself in the first month of exposure; this fact alone throws doubt on simple 'coupling' as the causative factor, because all fouling exposures involving unpainted copper-steel couples show immediate fouling of the 'cathodically protected' copper.

The observation-first made by us in 1942 in connexion with a series of immersed painted steel panels racked on 'Micarta' strips which in turn were bolted to plain iron angles - that 'run-down' of iron corrosion products over an antifouling paint inactivates the latter has undoubtedly been made by others, although we find no reference to it in any published reports. It is our belief that many cases of anomalous inactivation may be better attributed to this effect than to 'coupling'.

\section{Selective Fouling}

The occurrence of fouling in 'bands', either horizontal or vertical, near gross breaks in antifouling paint film on test panels where corrosion is actively going on has been the subject of much speculation ${ }^{3}$. Several of our test series show this phenomenon markedly.

The North Florida Test Station exposure site at Daytona Beach, Florida, is located near the mouth of an inlet; the tidal action is such that a maximum velocity 'up-stream' approximating to 4 m.p.h. when the tide is coming in is attained; this is followed by a period of relative quiescence, then the current flow reverses, reaching a 4 m.p.h. velocity 'down-stream' at low tide. Thus, tidal action is such that a semistratified layer of water sweeps across the face of the test panels except when excessive wind and wave action produces turbulence and counter-currents. Accordingly, corrosion products originating at bare areas or mechanical breaks in the film may be swept out and across the surface of intact paint, in a horizontal band roughly the width of the corroding spot. Photographs of several test panels demonstrating the phenomenon are presented in Fig. 1 .

Similar observations have been made at Kure Beach, Wilmington, N.C., where, however, the current flow is continuous, and in one direction only; here the area 'down-stream' of a corroding spot is always rust-stained and tends to foul well in advance of the 'up-stream' area.

We have observed the phenomenon taking place in substantially a vertical line with another series of panels bolted to, but insulated from, an unpainted steel overhead member. When fouling began, it was always the area immediately adjacent to the support at the top which fouled first, the fouling band being 